The entire proceedings should give a very useful upto-date version of modern surface chemistry in all its aspects, both pure and applied, and will take several years to digest.

The discussion at the Congress seemed to specialize in classical surface chemistry at the air/liquid and liquid/liquid interfaces, such as thermodynamics of adsorption at interfaces and micelles, evaporation. retardation, transport of material across liquid/liquid interfaces, formation of emulsions, the meaning of contact angles at the solid/gas/liquid line interface, long-range forces at solid surfaces and nucleation phenomena. It was truly astonishing to listen to the thermodynamic specialists expressing opposing views, with complete confidence that the opposing side was wrong and that they were fundamentally correct. It was somewhat horrifying to notice that the thermodynamic concepts and terms were frequently misused. For example, Harkins free energy term was repeatedly misquoted as a Gibbs free energy term, and systems used by Hill, Guggenheim, Harkins and Everett freely intermixed. It seems essential that some common system with defined symbols should be established once and for all.

There was relatively little discussion on the solid/ gas interface, presumably since there were very high-geared participants in the audience which possibly frightened off discussion, and unfortunately the chairmen were conscientious and ruthless about being on time with their programme. But there were some very interesting papers in this section, especially those dealing with perturbation effects of the adsorbing molecules on solid surfaces, and also of the solid surface on the adsorbing gas molecules. This was shown experimentally by infra-red adsorption of the molecules in the adsorbed phase. This work has immediate application to studies in catalysis and possible means of measuring changes in bulk properties of solids by changes in surface phenomena. There were some interesting papers, partly in review, on the surface energies of solids in relation to their chemistry, which has interesting possibilities for future work in this intriguing field.

Some workers in the solid/liquid interfacial field related all the occurring phenomena to the inherent roughness of the solid surfaces. Others seemed to have such smooth surfaces that they could measure attractive forces between solid surfaces at molecular distances apart. Each party was completely unconvinced by the arguments of the opposing side.

One of the applied subjects which aroused interest was the use of long-chain hydrocarbon alcohols in the form of condensed monolayers in retarding the evaporation of water. On the laboratory scale this is successful up to 90 per cent; on field trials on areas of about an acre the efficiency is about $30-40$ per cent, using alcohols spread from floats containing solid beads of the material. Hope was given that by using liquid spreaders in which the long-chain alcohol is soluble, the film could be spread and held on areas of square miles. Since water evaporates in Australia at the rate of about six million tons a year per square mile, the economic stimulus to this type of work is most pronounced. Papers dealing with the role of water molecules selectively adsorbing at crystal surfaces, either soluble in saturated water solutions or insoluble in the form of powders in the atmosphere, have very interesting practical implications: in the first case for the selective flotation of soluble salts, and in the second case for nucleation in cloud seeding experiments, where copper sulphide is shown to be the best seeding agent, and zinc sulphide, for example, one of the worst.

Ihe meeting presented a great opportunity for scientists of the Western world to listen to and to learn the methods of the Russian and Polish scientists, expressed mainly in English. 'I his was invaluable, since the Russians are more active in the field of surface chemistry than their Western colleagues, and their papers with references present a good record of their recent research.

From the enthusiasm shown by those producing original manuscripts and by participants at the discussion, there should be no difficulty for the organ. izers of the next International Congress to start thinking soon on a programme for the third world meeting.

$$
\text { J. H. Schulman }
$$

\section{STUDIES ON FERTILITY}

$T$ $H E$ seventh annual conference of the Society for the Study of Fertility was held in Exeter on July 5 and 6 . As in the past, papers were read on clinical, basic scientific and veterinary subjects covering the field of fertility in its broadest sense.

From the Liverpool School, already well known. for its contributions to testicular and male accessory. organ anatomy and physiology, came two further papers. E. J. Clegg studied changes in the coagulating glands and seminal vesicles in rats by killing litter mates at weekly intervals. He found the former to be histologically more labile than the latter and, since there was no simple relation between age, testicular histology and the fructose content of the coagulating gland, concluded that fructose content was not a reliable indicator of hormone production. In discussion, it was pointed out by $T$. Mann that the fructose content of the secretions, rather than of the gland cells, was likely to be of more significance, while J. Macleod drew a parallel, with Leydig cell secretion rather than numbers as of importance from the point of view of testis hormone production. E. W. Macmillan, also from Liverpool, has continued his studies on sperm transport through the epididymis of the rat. Since ipsilateral orchidectomy after the introduction of radio-opaque medium into the vasa efferentia does not affect the time of passage through the vas deferens, it is concluded that the vis a tergo from the testis is of no importance. The rate was similarly unaffected by ligation of the terminal efferential tubule or by high ligation of the ductus epididymidis. Trypan blue particles are transported in the same way as radio-opaque media.

A symposium on the methods of testing for spermicidal activity was opened by T. Mann (Cambridge), who pointed out that no single biochemical mechanism was affected by all spermicides, and that there were at least three groups of these: enzyme and competitive inhibitors, sulphydryl-binding substances, and surface-active agents. Clare Harvey (Exeter) discussed the dichotomy of opinion on whether the end-point for tests should be the concentration required to kill within a fixed time, or the time required to kill at a fixed concentration. She preferred the former (modified Baker test of total spermicidal activity). B. Carruthers (London) said that at the Family Planning Association Laboratories, satisfactory results had been obtained with the modified Baker test. He also mentioned his studies with the Davidzon contact test and how the results could be affected by various factors, especially 
ingredients in the vehicle themselves not regarded as spermicides. P. E. Lindahl (Sweden) described how he has replaced the upper and lower glass surfaces of the cell used in the Davidson test by semipermeable membranes, permitting the access of oxygen, since he believes conditions within the vagina to be aerobic, not anaerobic. J. Macleod (New York) said that a special laboratory has been set up at the Sanger Bureau of the International Planned Parenthood Federation, with the express purpose of investigating all the existing methods of spermicidal testing. He himself believed that fundamental studies on spermigration are urgently needed.

There were two papers on the effects on pregnancy of certain antimetabolites and nucleotoxic compounds. J. M. Robson and D. Jackson (London) considered three groups of substances-spindle poisons, such as podophyllotoxin, colchicine and demecolcine; mitotic poisons, such as chlorambucil and nitrogen mustards; and antimetabolites, such as 6-mercaptopurine and furazolidone. Most of these were effective in interrupting pregnancy, some even before the stage of implantation; but, in general, the therapeutic ratio was too low for them to have any practical value. Of those agents which were effective before implantation, the antimetabolites seemed most promising. J. Yudkin, B. P. Wiesner and Miriam Wolfe had found $\beta$-peltatin less active, but with a higher therapeutic ratio than podophyllotoxin. $\alpha$-Peltatin was more active and less toxic than $\beta$-peltatin. Two doses, given on successive days, were more effective than a single dose. Demecolcine was very effective, but the escaped litters after marginal doses showed many congenital abnormalities and the surviving offspring had impaired fertility. It was promising for future research that slight changes in chemical structure markedly influenced both effectiveness and toxicity.

M. G. Scott and Patricia P. Scott (London) have made detailed studies of the effects on the reproductive organs of cats of chronic infections, dietary inadequacies and ligation of the pancreatic duct. These all led to retardation of development and regression of the gonads and accessories. In the testes abnormal cell types were seen, while poor follicular activity was found in the ovaries. It was concluded that the primary effect in all cases was malnutrition rather than a direct influence of the chronic infection, and that it was exerted on the anterior pituitary body, the gonadal changes being secondary.

Hilda M. Bruce (London) said that all the hamsters at present in the western hemisphere were descendants of a single litter found at Aleppo twenty-five years ago. About twelve varieties were now recognized. Of these, the ruby-eyed fawn mutant showed genetic sterility in the male. Her investigations on this revealed that fertility is confined to a period of 2-3 weeks after puberty, the subsequent progressive infertility being due to increasing defect of spermato. genesis. The testicular histology showed disorganization of isolated tubules even in young and still fertile animals; this process progressed with advancing age so that by 150 days sterility was complete. Multinucleate cells (similar to those found by Scott and Scott in their subnormal cats) appeared. In the ensuing discussion, T. Mann pointed out that copper-containing enzymes are implicated in both pigment formation and spermatogenesis, suggesting a possible enzyme defect as the basis for the genetic sterility.
Delphine M. V. Parrott (London) described a technique for orthotopic ovarian grafting which avoided the difficulties of surgical removal of the ovaries in the recipient mouse, by subjecting the animals to $900 \mathrm{r}$. of whole-body irradiation, followed by the injection of bone marrow from other mice. A later modification was to give two successive doses of $450 \mathrm{r}$. since, although the effect on the ovary is cumulative, the systemic effects of a given dose (if not lethal) are relatively short-lived. Orthotopic grafts made four weeks after irradiation proved fertile, but if grafting were delayed until nine weeks after irradiation, fertility was reduced, perhaps because of the reduced blood supply to the very atrophic ovarian remnant.

J. L. Hancock (Cambridge) has made an exam. ination of cleaved ova recovered after natural or artificial insemination of sows in order to assess the fertilization-rates. He found 90.5 per cent cleavage after natural matings, but only $21 \cdot 7-47 \cdot 8$ per cent after artificial insemination. The highest rates with the latter were obtained when undiluted semen or semen diluted with egg-yolk glucose phosphate diluent was used $(46 \cdot 2$ and $47 \cdot 8$ per cent cleavage). When semen diluted as above but stored for twentyfour hours at $5^{\circ} \mathrm{C}$. was used, the rate was only 21.7 per cent, and when semen diluted with seminal plasma was inseminated the rate was $22 \cdot 2$ per cent. It was also observed that the number of spermatozoa in the zona pellucida of recovered eggs was in general considerably lower after artificial insemination than after natural mating. There seems little doubt that the efficiency of artificial insemination compares unfavourably with that of natural mating.

G. I. M. SWYER

\section{AGRICULTURE AT CAMBRIDGE}

A COLLECTION of eleven review articles which $A$ have prefaced the Memoirs of the School of Agriculture, Cambridge, over the past few years has recently been published as the first volume of "Agricultural Research and Teaching at Cambridge"*. As Sir Frank Engledow points out in a foreword it is always profitable to ponder objectives and achievements of the past in deciding courses for the future, and these articles review in some detail the researches and achievements by members of the staff of the School of Agriculture in particular fields. A historical review of researches in the physiology of reproduction is made by $\mathrm{F}$. H. A. Marshall in which he traces the development of this subject from the founding of a university lectureship in agricultural physiology in 1908. Kenneth Smith summarizes twenty years of virus research, and G. D. H. Bell describes how the application of genetical principles to the breeding of agricultural plants was the inspiration for the establishment of the Plant Breeding Institute in 1912. The researches in animal nutrition are reviewed by E. T. Halnan. The Horticultural Research Station was opened in 1922, and R. M. Woodman describes the changes in the character of the work which have taken place since then. 'The study of agricultural economics commenced as early as 1896 with the endowment of a lectureship in this subject by Sir Walter Gilbey,

* University of Cambridge: School of Agriculture. Agricultural Research and Teaching at Cambridge, Vol. 1 (comprising Review Series, Nos. 1-11). Pp. 72. (Cambridge : University School of Agriculture, 1957.) 7s. $6 d$. 